\title{
Evidence for an association between rheumatoid arthritis and autoimmune endocrine disease
}

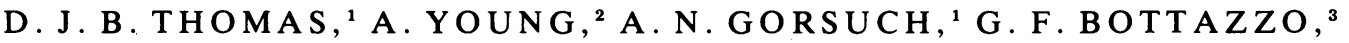 \\ ANDA. G. CUDWORTH ${ }^{1}$
}

From the 'Department of Diabetes and Immunogenetics, St Bartholomew's Hospital, and the Departments of ${ }^{2}$ Rheumatology and ${ }^{3}$ Clinical Immunology, Middlesex Hospital, London

SUMMARY Evidence is presented for the first time of a significantly increased prevalence of type 1 (insulin-dependent) diabetes in the close relatives of patients with rheumatoid arthritis. Thirtynine $(13 \%)$ of 295 patients with classical or definite rheumatoid arthritis had a first or second degree relative with type 1 diabetes and $38(13 \%)$ had a close relative with autoimmune thyroid disease. These findings could be compatible with a possible common genetically determined mechanism of susceptibility to both diseases.

Recently there has been considerable renewed interest in the pathogenic basis of several common diseases. A clearer understanding of the underlying genetic susceptibility to both type 1 diabetes mellitus and rheumatoid arthritis has emanated from studies of the HLA system. Population studies have shown that there is a positive association of both HLA DR3 and DR4 with type 1 diabetes mellitus ${ }^{1-3}$ and of HLA DR4 (DW4) with rheumatoid arthritis. ${ }^{45}$

Interest in the possible relationship between these 2 immune related diseases was stimulated by our observations in 2 large family studies that $12-14 \%$ of young type 1 diabetic probands had a first or second degree relative with rheumatoid arthritis. ${ }^{67}$ The familial aggregation of organ specific autoimmune endocrinopathies is well recognised, and attention has been drawn to a possible relationship between rheumatoid arthritis and Hashimoto's thyroiditis. ${ }^{89}$ Other autoimmune diseases such as myasthenia gravis also occur more frequently in subjects with rheumatoid arthritis. ${ }^{10}$

\section{Patients and methods}

Two hundred and ninety-five patients, age range 21-83 years (mean age 52 years), with classical or definite rheumatoid arthritis (American Rheumatism Classification ${ }^{11}$ ), were randomly ascertained by 2 of us from 2 rheumatology clinics. Two hundred and eight $(70 \%)$ were seropositive for rheumatoid Accepted for publication 1 April 1982.

Correspondence to Professor A. G. Cudworth, Department of Diabetes and Immunogenetics, St Bartholomew's Hospital, West Smithfield, London EC1A 7BE. factor. A detailed family history was obtained from each patient with particular reference to diabetes, thyroid disease, pernicious anaemia, myasthenia gravis, and other autoimmuine diseases. Type 1 diabetes was characterised as carefully as possible by the age of onset, severity at presentation, and dependence on insulin. In patients with a positive family history of type 1 diabetes the relative with this disease was contacted directly in $80 \%$ of cases. In the remaining patients we have strong corroborative evidence that they had this disease. The findings were compared with those obtained from 307 patients, age range 21-91 years (mean age 53 years), with degenerative arthritis attending the same clinics. A family history of rheumatoid arthritis was recorded as positive only if the description and diagnosis appeared unequivocal.

The 2 groups of patients studied were comparable in age distribution, and the prevalence of females was not grossly dissimilar in them $(65 \%$ and $58 \%$ respectively). Organ specific antibodies to islet cells, thyroid, and stomach were investigated where possible by previously described techniques. ${ }^{72}$ Seropositivity for rheumatoid arthritis was established in all patients by a standard latex test and rheumatoid arthritis haemagglutination assay (RAHA) assay. Statistical analysis was performed by chi-square testing and Fisher's exact test.

\section{Results}

PREVALENCE OF RHEUMATOID ARTHRITIS Sixty-seven $(22 \%)$ patients with rheumatoid arthritis 
( $85 \%$ seropositive) had a first-degree relative with the same disease. It is of interest that 44 of these were parents and in only 24 instances was a sibling affected. This contrasts with a history of rheumatoid arthritis in first-degree relatives of $16(5 \cdot 3 \%)$ patients with degenerative arthritis $(p<0.0001)$. Similar results were obtained for the prevalence of a positive family history for rheumatoid arthritis in second-degree relatives $(8.4 \%$ and $3.9 \%$ respectively). These findings confirm the familial aggregation of rheumatoid arthritis.

\section{PREVALENCE OF DIABETES MELLITUS}

The prevalence of type 1 (insulin-dependent) diabetes in the close relatives of the 2 groups of patients with rheumatoid arthritis and degenerative arthritis is shown in Table 1 . A definite association between rheumatoid arthritis and type 1 diabetes mellitus is demonstrated. Seventeen rheumatoid probands had a first-degree relative with type 1 diabetes. Twentytwo rheumatoid probands had a second-degree relative with type 1 diabetes. This is significantly different from findings in the group with degenerative arthritis, particularly when probands with a first or second degree relative affected were combined $(p<0.0001)$. The overall prevalence of type 1 diabetes among all first-degree relatives in both groups is shown in Table 2 . The presence of a positive family history of diabetes mellitus in relation to seropositivity for rheumatoid arthritis was also investigated. The majority $(87 \%)$ of rheumatoid patients with a close relative affected by type 1 diabetes were seropositive $(\mathrm{p}<0 \cdot 001)$.
PREVALENCE OF OTHER AUTOIMMUNE

DISEASE

Twenty-five patients $(8.5 \%)$ with rheumatoid arthritis were suffering from another autoimmune disease (Graves's disease 7, primary myxoedema 8 , pernicious amaemia 6 , diabetes mellitus 2 , myasthenia gravis 1 and Sjögren's syndrome 1). In contrast there were $14(4 \cdot 6 \%)$ patients with degenerative arthritis who had another autoimmune disease (Graves's disease 8, and myxoedema 6).

There was also a striking association between rheumatoid arthritis and thyroid disease in close relatives. Thus $38(13 \%)$ probands with rheumatoid arthritis had a first- or second-degree relative with either Graves's disease or primary myxoedema. In the group with degenerative arthritis, combined thyroid disease in close relatives amounted to 18 $(6 \%)$ patients $(p<0.005)$. The prevalence of pernicious anaemia did not differ significantly between the 2 groups.

\section{PREVALENCE OF ORGAN SPECIFIC \\ AUTOANTIBODIES}

Among the 169 rheumatoid patients tested for islet cell antibodies (ICA) 3 sera were found to be positive; none of these subjects was diabetic. In 2 instances there was a first-degree relative with type 1 diabetes, and the third ICA-positive patient had a second-degree relative with type 1 diabetes. Of the 412 sera tested from the degenerative arthritis group none was positive for ICA.

The distribution of thyroid microsomal and gastric parietal cell antibodies is shown in Table 3. There was

Table 1 Probands with a family history of type 1 (insulin-dependent) or type 2 (insulin-independent) diabetes

\begin{tabular}{llllll}
\hline & \multicolumn{2}{l}{$\begin{array}{l}\text { Type 1 (insulin- } \\
\text { dependent) }\end{array}$} & & \multicolumn{2}{l}{$\begin{array}{l}\text { Type 2 (insulin- } \\
\text { independent) }\end{array}$} \\
\cline { 2 - 3 } \cline { 5 - 6 } & 1st degree & 2nd degree & & 1st degree & 2nd degree \\
\hline Rheumatoid arthritis $(\mathrm{n}=295)$ & $17(5 \cdot 7 \%)$ & $22(7 \cdot 5 \%)$ & & $15(5 \cdot 0 \%)$ & $21(7 \cdot 1 \%)$ \\
Degenerative arthritis $(\mathrm{n}=307)$ & $\begin{array}{c}7\left(2 \cdot 2^{\circ}\right) \\
\mathrm{p}<0.05\end{array}$ & $\begin{array}{c}5(1.6 \%) \\
\mathrm{p}<0.001\end{array}$ & & $\begin{array}{l}15(4 \cdot 8 \%) \\
\mathrm{p}: \mathrm{NS}\end{array}$ & $\begin{array}{l}12(3 \cdot 9 \%) \\
\mathrm{p}: \mathrm{NS}\end{array}$ \\
\hline
\end{tabular}

Combined prevalence of rheumatoid probands with either a first- or second-degree relatives with type 1 diabetes $=39(13 \cdot 2 \%)($ compared with degenerative arthritis group, $\mathrm{p}<0.0001$ )

Table 2 Prevalence of type 1 diabetes in first degree relatives

\begin{tabular}{lllll}
\hline & $\begin{array}{l}\text { Total number of } \\
\text { 1st-degree relatives }\end{array}$ & $\begin{array}{l}\text { Mean number of } \\
\text { relatives/proband }\end{array}$ & $\begin{array}{l}\text { 1st-degree relatives } \\
\text { with type 1 } \\
\text { diabetes mellitus }\end{array}$ & $\begin{array}{l}\text { Prevalence in } \\
\text { 1st-degree } \\
\text { relatives }\end{array}$ \\
\hline Rheumatoid arthritis $(\mathrm{n}<295)$ & 2081 & $7 \cdot 1$ & 19 & $0.9 \%$ \\
Degenerative arthritis $(\mathrm{n}<307)$ & 2299 & $7 \cdot 5$ & 8 & $0 \cdot 4 \%$ \\
\hline
\end{tabular}


Table 3 Organ-specific autoantibodies in probands

\begin{tabular}{lllc}
\hline Probands & $\begin{array}{l}\text { Islet cell } \\
\text { antibody }\end{array}$ & $\begin{array}{l}\text { Thyroid } \\
\text { microsomal } \\
\text { antibody }\end{array}$ & $\begin{array}{l}\text { Gastric } \\
\text { parietal } \\
\text { cell }\end{array}$ \\
\hline $\begin{array}{c}\text { Rheumatoid } \\
\text { arthritis }\end{array}$ & $3 / 169$ & $77 / 233$ & $38 / 233$ \\
$\begin{array}{c}\text { Degenerative } \\
\text { arthritis }\end{array}$ & $0 / 41$ & $37 / 218 \quad \begin{array}{c}10 / 218 \\
(p<0 \cdot 0005)\end{array}$ \\
\hline
\end{tabular}

a striking excess of both thyroid and gastric autoantibodies in the rheumatoid patients $(\mathrm{p}<0.0005)$.

\section{Discussion}

Previous studies on rheumatoid arthritis and diabetes mellitus ${ }^{13-15}$ have failed to show any association between these 2 common diseases. The reasons for this are probably the lack of previously agreed criteria for the characterisation of rheumatoid arthritis and the failure to recognise the pathogenic heterogeneity of diabetes.

The new important observation from this study is the significant excess of type 1 diabetes mellitus in the close relatives of patients with classical or definite rheumatoid arthritis. This confirms suggestive evidence from 2 family studies of type 1 diabetes, the first including 141 families each with a diabetic child, and the second including 120 families with 2 or more affected children. ${ }^{6}{ }^{7}$ In both cases the mean age of the probands was 14 years. Established diagnoses or classical descriptions of rheumatoid arthritis in firstor second-degree relatives or both were given by $12 \%$ and $14 \%$ of the families in the respective studies. Although fully aware of the problems of ascertainment in this type of study we feel confident that the familial aggregation of type 1 diabetes and rheumatoid arthritis in these separate studies reflects a real association between the 2 diseases. An important question is whether these findings could reflect an aetiological link at the genetic level (a common environmental factor is perhaps less likely, because second- as well as first-degree relatives are affected). One possible mechanism is suggested by HLA population studies: both conditions show positive associations with HLA DW4 and DR4, although the frequencies of DW3 and DR3 are increased only in type 1 diabetes. ${ }^{1-4}$ One interpretation is that the same HLA-linked immune response gene is controlling the susceptibility to both disease in linkage disequilibrium with DW4 DR4. By the same token conditions which are not DR4-associated should not show any increase in the 'rheumatoid' families. This is indeed so for type 2 diabetes. In addition we found a signifi- cant excess of autoimmune thyroid disease in the families of rheumatoid probands compared with the control group. Pernicious anaemia was evenly distri-

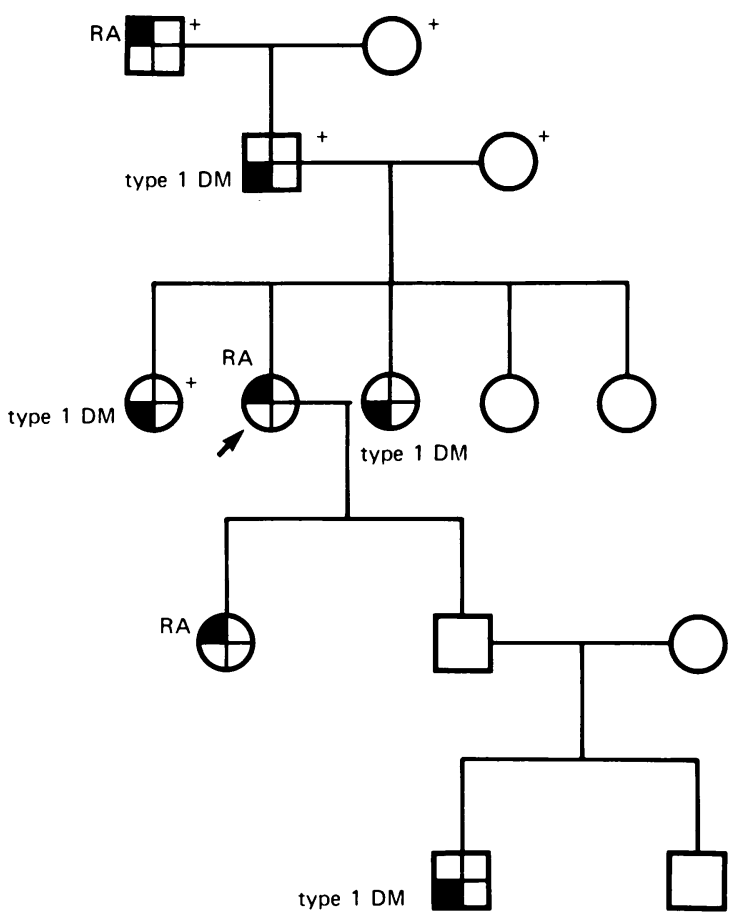

Fig. 1 A pedigree demonstrating the familial aggregation of type 1 diabetes and rheumatoid arthritis.

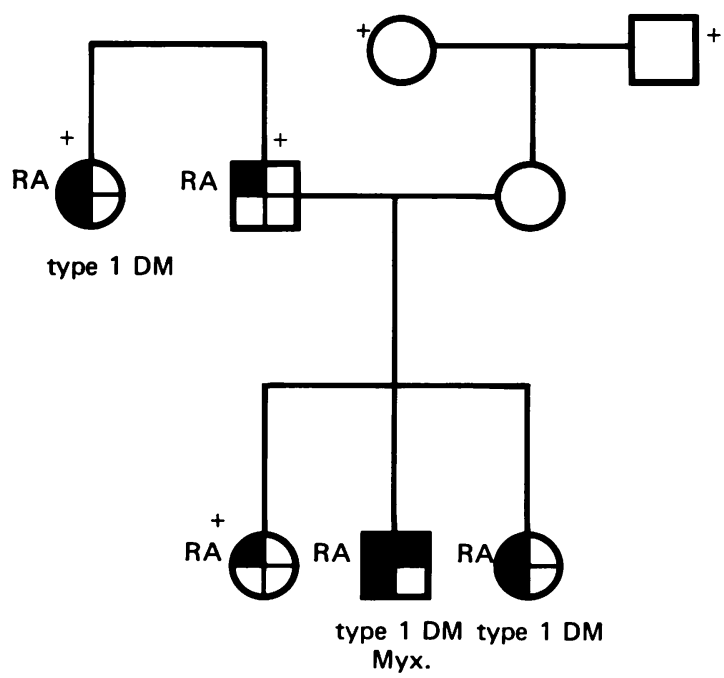

Fig. 2 A pedigree demonstrating 3 subjects with coexistent type 1 diabetes and rheumatoid arthritis. The proband also had myxoedema. 
buted, and there were no cases of Addison's disease or myasthenia gravis in either family group.

The familial aggregation of rheumatoid arthritis has also been a controversial issue, ${ }^{16}{ }^{17}$ but it is likely from this and other more recent studies, including investigations of identical twins, ${ }^{18}$ that there is a definite familial pattern to the disease. The rheumatoid probands showed an excess of thyroid and gastric autoantibodies, confirming the findings in an earlier smaller study.$^{19}$ There was also more coexisting autoimmune disease in these subjects. We ascertained 7 unrelated patients with coexisting type 1 diabetes and rheumatoid arthritis, and it is of interest that the diabetes in these patients has many of the features of 'type $1 \mathrm{~B}$ ' or 'primary autoimmune' diabetes. ${ }^{20}$ The mean age at diagnosis of insulin-dependent diabetics was 41 , and most patients had organ-specific antibodies, including persistent ICA ( $3 / 6$ cases tested), thyroid and/or gastric antibodies $(4 / 6)$, and adrenal antibodies in the absence of Addison's disease (2/6). Two examples of the strong familial aggregation of those diseases are shown in Figs. 1 and 2.

In order to test the hypothesis that the same or different HLA-linked susceptibility genes are operating in determining predisposition to these related diseases it would be of interest to HLA-genotype families in which one sibling has rheumatoid arthritis and another sibling has type 1 diabetes or another autoimmune endocrine disease.

We thank Dr E. C. Huskisson and Dr D. V. Doyle for allowing us to study their patients at the Rheumatology Clinic at St Bartholomew's Hospital. We also thank Professor I. M. Roitt and Professor Deborah Doniach for their helpful comments on the manuscript.

This work was supported by a grant from the Kroc Foundation and AY is supported by the Arthritis and Rheumatism Council.

\section{References}

1 Cudworth A G. Current concepts of aetiology: type 1 (insulin dependent) diabetes mellitus. In: Bellingham A J, ed. Advanced Medicine London: Pitman Medical, 1980: 16: 123-35.

2 Christy M, Green A, Christau B, et al. Studies of the HLA system and insulin dependent diabetes. Diabetes Care 1979; 2: 209-14.
3 Deschamps I, Lestradet $\mathrm{H}$, Bonaiti $\mathrm{C}$, et al. HLA genotype studies in juvenile insulin dependent diabetes. Diabetologia 1980; 19: 189-93.

4 Stastny P. Genetic control of the immune response and susceptibility for rheumatoid arthritis, lupus erythematosus and related diseases. In: Franklin E C, ed. Clinical Immunology Update. New York: Elzevir, 1981: 31-57.

5 Woodrow J C, Nichol F E, Zaphiropoulos G. DR antigens and rheumatoid arthritis, a study of two populations. Br Med J 1981; 283: 1287-9.

6 Walker A, Cudworth A G. Type 1 (insulin dependent) diabetic multiplex families: mode of genetic transmission. Diabetes 1980 ; 29: $1036-9$.

7 Gorsuch A N, Dean B, Bottazzo G F, Lister J, Cudworth A G Evidence that type 1 diabetes and organ specific autoimmunity have different genetic determinants. Br Med J 1980; 280: 145-7.

8 Buchanan W W, Crooks J, Alexander W D, Koutras D A, Wayne E J. Association of Hashimoto's thyroiditis and rheumatoid arthritis. Lancet 1961; i: 245-8.

9 Becker K L, Ferguson R H, McConahey W M. The connective tissue diseases and symptoms associated with Hashimoto's thyroiditis. N Engl J Med 1963; 208: 277-80.

10 Oosterhuis J K, De Hass W H. Rheumatic disease in patients with myasthenia gravis. Acta Neurol Scand 1968; 44: 219-27.

11 Ropes M W, Bennett G A, Cobb S, Jacox R. Jessar R A. The revised American Rheumatism Association classification. Ann Rheum Dis 1959; 18: 49-55.

12 Bottazzo G F, Florin-Christenson A, Doniach D. Islet cell antibodies in diabetes mellitus with autoimmune polyendocrine deficiencies. Lancet 1974; ii: 1279-83.

13 Jarvinen K A J. A study of the interrelations of rheumatoid arthritis and diabetes mellitus. Ann Rheum Dis 1960; 19: 226-30.

14 Linos A, Worthington J W, Palumbo P J, O'Fallon W M, Kurland L T. Occurrence of Hashimoto's thyroiditis and diabetes mellitus in patients with rheumatoid arthritis.J Chron Dis 1980; 33: 73-7.

15 Short C L, Bauer W, Reynolds W E. Rheumatoid Arthritis. Cambridge, Mass: Harvard University Press, 1957: 118-24.

16 Lawrence J S. Rheumatoid arthritis: nature or nurture. Ann Rheum Dis 1970; 29: 357-79.

17 Lawrence J S. Rheumatism in Populations. London: Heinemann, 1977: 242-3.

18 Dixon A, Sanger R. Stratton F. Arthritis and Rheumatism Council twin survey. Ann Rheum Dis 1970; 29: 365-8.

19 Corbet M, Downs J M, Schmid F R. A clinical and serological study of rheumatoid arthritis. Ann Rheum Dis 1967; 26: 487-93.

20 Bottazzo G F, Cudworth A G, Moul D J, Doniach D, Festenstein $\mathrm{H}$, Evidence for a primary autoimmune type of diabetes mellitus (type 1b). Br Med J 1978: ii: 1253-5. 